\title{
Handover Analysis in WIMAX using NPS and RCS
}

\author{
Manzar Ahmad \\ M.Tech scholar \\ Dept. of ECE \\ SHIATS, Allahabad
}

\author{
Rajeev Paulus,PhD \\ Asst. Professor \\ Dept. of ECE \\ SHIATS, Allahabad
}

\author{
A.K. Jaiswal \\ Professor and H.O.D \\ Dept. of ECE \\ SHIATS, Allahabad
}

\author{
Aditi Agarwal \\ Asst. Professor \\ Dept. of ECE \\ SHIATS, Allahabad
}

\begin{abstract}
WiMAX can provide at home or mobile internet access across whole cities or countries. It provides enhance data rates as compared to digital subscriber line (DSL).It also provide support for mobile wireless access beside support for wireless broadband access (BWA).Due to the high traffic load in the cell problems like blocking, handover failure, forced termination and of not completed call arises. Therefore, two channel allocation scheme Non priority scheme (NPS) and Reserve channel scheme (RCS) has been proposed in Wimax.
\end{abstract}

\section{Keywords}

Wi-max, Channel Allocation, Reserved Channel Scheme, Non Prioritize Channel Scheme.

\section{INTRODUCTION}

Channel allocation procedure are different for Wi-max as it has two types fixed and mobile. In fixed WiMAX (IEEE $802.16 \mathrm{~d}$ ) users with no mobility (mainly broadband, home or office user are present. In mobile Wi MAX (IEEE 802.16e) we have both, fixed and mobile users [2]. So here mobility conditions come into account and the inter-cell movement of users cannot be ignored. So here the channel allocation scheme used here is (FCA and DCA). In mobile WiMAX we have both types of users, fixed and mobile, so for fixed users (broadband) there is a need to provide fixed channels (permanent channels). Reason for this is so that they never face blocking. So now a permanent set of channels also need to be allocated in the network. The cell size supported by a WiMAX cell may range upto $50 \mathrm{~km}$ in radius so number of channels to be allocated to a specific cell maybe more than even 200 channels. [2] Now as the permanent channel are assigned due to high traffic load probability like blocking $(\mathrm{Pb})$, probability of handover failure $(\mathrm{Ph})$, forced termination (Pft) and of not completed calls (Pnc) takes place therefore the concept of RCS and PCS comes in order to overcome these different types of blocking. Let us now discuss RCS and NPS in detail.

\section{SYSTEM DESCRIPTION}

NPS means NON Priority scheme, as the name suggest there is no priority for calls so it is basically a first come and first serve scheme there are no permanent channel any user who makes a first attempt will be assigned a channel. This scheme is disadvantageous when all the channels are busy and a new call attempt is blocked[4].In case of handover occurrence when a new user will enter the cell the call will be dropped if channels are busy. In fixed WiMAX broadband office users, fixed WiMAX broadband home users, mobile WiMAX broadband users and cell phone users all will have the same priority in NPS. No permanent channel allocation is supported by NPS so it can be concluded that in fixed broadband office use where disconnection is intolerable may also face blocking if no empty channels are available.[3]
RCS- This is a reserve channel scheme which means that channels are reserved for various kind of jobs. These include call attempt, handover, and permanent channel allocation. Highest priority is given to permanent channel allocation then to handover and then to call attempts. Different priority are assigned to hand over and permanent channel, no allocation is there for new calls. For example if $\mathrm{N}$ channels are there then $\mathrm{H}$ are allotted to handover ,P channels to permanent channels and remaining available channels are given to new calls. In the same way reserve channel used for permanent allocation are never used for handover and vice -versa.

\subsection{Method of Analysis for NPS and RCS in Wi-Max}

- Blocking probability (Pb)-The condition in which all the channels available in a cell are busy and an attempt to make a call is rejected. In this case user will receive a network busy message.

- Handover Failure Probability (Ph)-This is the condition when the user on a call enters a cell and the call is dropped due to unavailable channels in that cell (handover failure).

- Forced Termination Probability (Pft)-This is the condition when a mobile job previously accepted by system later rejected due to a handover failure after successful handover.

- Probability of Not Completed Calls (Pnc)-This is the condition when all the calls were not completed due to any of the above scenarios i.e. Blocking probability $(\mathrm{Pb})$, Handover Failure Probability $(\mathrm{Ph})$, Forced Termination Probability (Pft).

\subsection{DESCRIPTION OF PARAMETERS}

For parameters it is assumed here that new job attempts can be a call attempt or a wireless broadband connection and handover arrivals in the cell follow Poisson distribution.[7] Channel occupancy time is distributed exponentially (channel occupancy time is the time for which channel is occupied for a job or handover process). Here in the cell, Job Arrival Intensity is represented by $\lambda \mathrm{o}$, Handover job arrival intensity is represented by $\lambda \mathrm{hi}$, Handover Call Departure Intensity is represented by $\lambda$ ho, and Permanent Job Arrival Intensity is represented by $\lambda p$, Permanent job arrival intensity is kept constant because number of permanent jobs in the cell will always be same as they are fixed. Mobile user arrival intensity and handover arrival intensity may change according to the traffic conditions in the cell. Service intensity for a job until it leaves the cell (handover involved) is $\mu$ and for the job until it is completes within the cell (no handover) is $\eta$. Further it is assumed here that if a channel is allocated to a mobile user it will only be released if the connection ends or a handover is performed to a neighboring cell. In [3] it is considered that if total number of servers is $\mathrm{j}$, then total probability is given by 
Pj. In WiMAX we have an additional parameter i.e. Permanent Job Arrival Intensity, represented by $\lambda p$. This parameter will have no effect on NPS, so NPS results for WiMAX will be same as for PCS.

For simulation 90 busy channels are taken. MATLAB simulation tool is used to analyze the performance of Handover condition in WIMAX .HANDOFF facility can be analyzed with the help of these parameter like Blocking Probability $(\mathrm{Pb})$, Handover Failure Probability $(\mathrm{Ph})$, Forced Termination Probability (Pft), Probability of Not Completed Calls (Pnc).

Table

\begin{tabular}{|c|c|c|}
\hline $\begin{array}{c}\text { Total Number Of } \\
\text { Channels }\end{array}$ & $\begin{array}{c}\text { Channels Reserved } \\
\text { For Handovers }\left(\mathrm{C}_{\mathrm{H}}\right)\end{array}$ & $\begin{array}{c}\text { Permanent } \\
\text { Assigned Channels } \\
(\mathrm{K})\end{array}$ \\
\hline 90 & 30 & 15 \\
\hline 90 & 25 & 15 \\
\hline 90 & 15 & 10 \\
\hline
\end{tabular}

\section{RESULT AND DISCUSSION}

\subsection{Interpretation Of Call Blocking} Probability

$\mathbf{P}_{\mathbf{B}}$ for both NPS and RCS in each simulation result in Figures $(1,2$, and 3$)$ increases with increase in the number of busy channels. Order of $\mathrm{Pb}$ is RCS with permanent channels $>\mathrm{RCS}$ with no permanent channels > NPS. This is because in NPS all channels are available for all kind of jobs (mobile, fixed or handover), in other words maximum number of channels are available for any kind of job. In RCS with no permanent channels, channels are reserved for handover so for new job initiated in the system remaining channels are less as compared to NPS, so Pb is higher than NPS. Similarly in RCS with permanent channels both permanent and reserved channels are present, so the remaining channels for a new job are less as compared to the other two schemes, so $\mathrm{Pb}$ in this case is higher than the other two. In case of NPS it can be seen that $\mathrm{Pb}$ remains same for all of the scenarios because here in NPS there are no permanent or reserve channels.

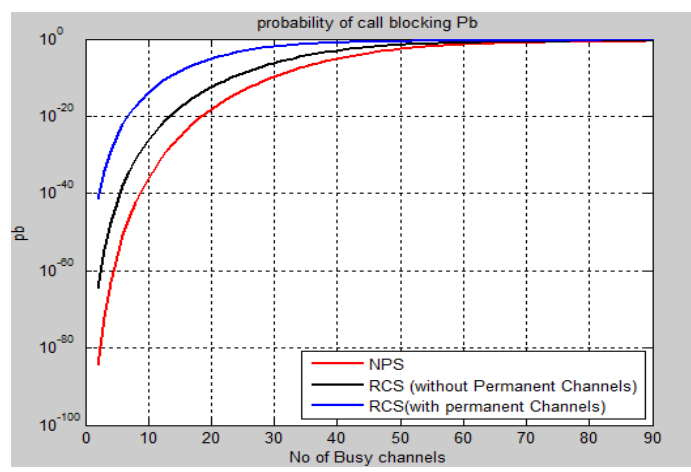

Figure.1 Call blocking Probability $\left(\mathbf{P}_{\mathrm{b}}\right)$ with No. of channel= 90, $k=15$ and $C_{\mathrm{H}}=30$.

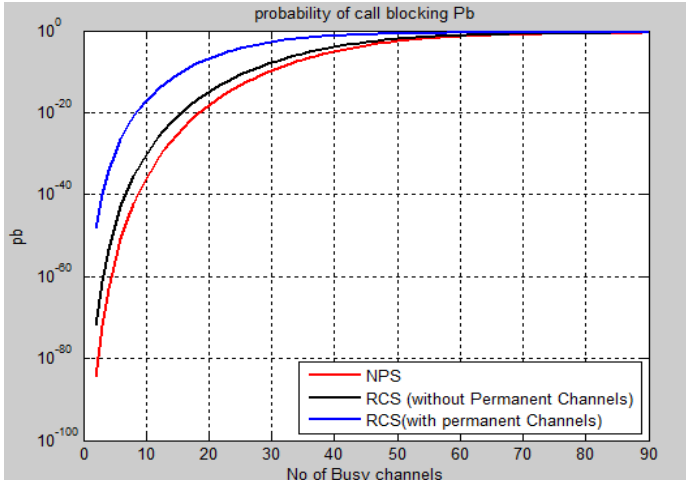

Figure.2.Call blocking Probability $\left(P_{b}\right)$ with No. of channel= 90, $k=15$ and $C_{\mathrm{H}}=25$

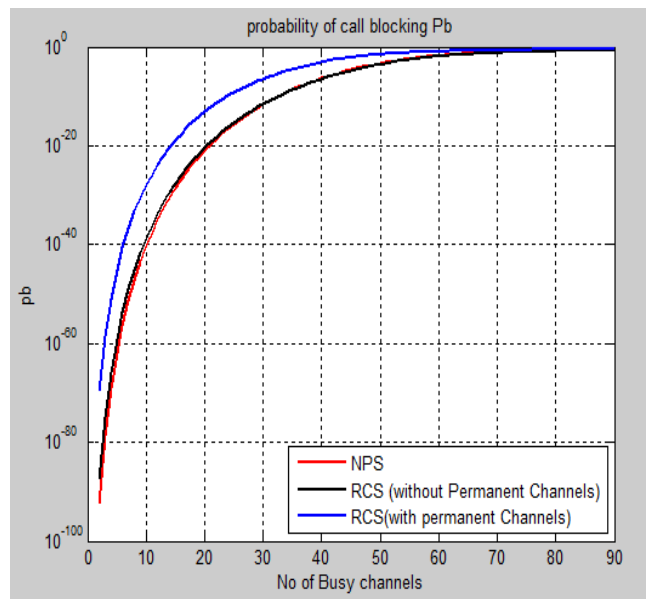

Figure.3.Call blocking Probability $\left(\mathbf{P}_{\mathbf{b}}\right)$ with No. of channel $=90, k=10$ and $C_{\mathrm{H}}=15$

\section{HANDOVER FAILURE PROBABILITY $\left(\mathbf{P}_{\mathbf{h}}\right)$}

$\mathrm{Ph}$ for both NPS and RCS in each simulation result in Figures $(4,5$, and 6$)$ increases with increase in the number of busy channels. Ph for NPS is greater than both RCS schemes. This is because in $\mathrm{Ph}$ if it is considered that all channels in the cell are busy then for NPS there are no channels available for handover purpose, so a handover arrival job in the cell will be terminated. On the other hand in RCS we have reserved channels for handover purpose, so if all $n$ channels are busy and a handover job arrives in the cell it will be accommodated. Also Ph for RCS with permanent channels is less than RCS with no permanent channels

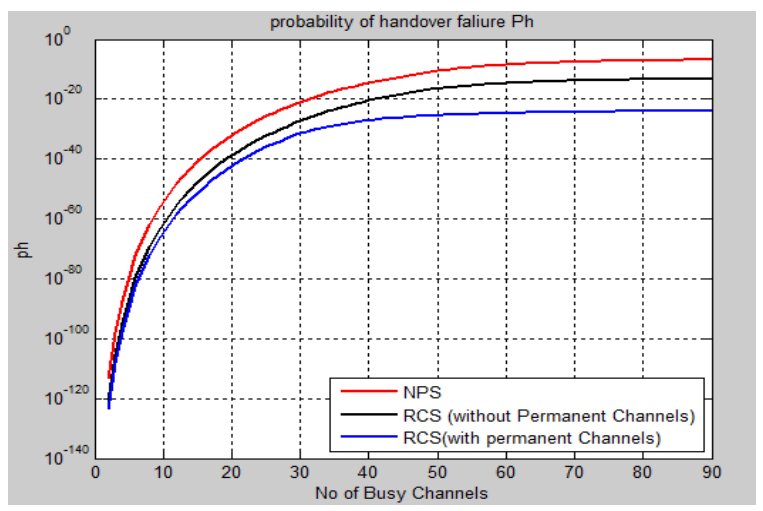

Figure.4.Handover Failure Probability $\left(P_{h}\right)$ with No. of channel= 90, $k=15$ and $C_{\mathrm{H}}=30$. 


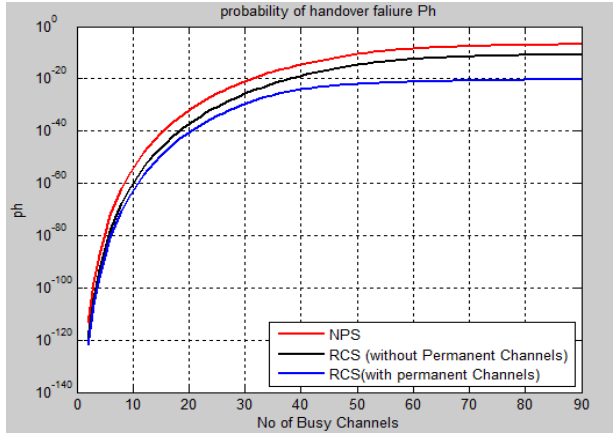

Figure.5.Handover Failure Probability $\left(P_{h}\right)$ with No. of channel $=90, k=15$ and $C_{\mathrm{H}}=25$

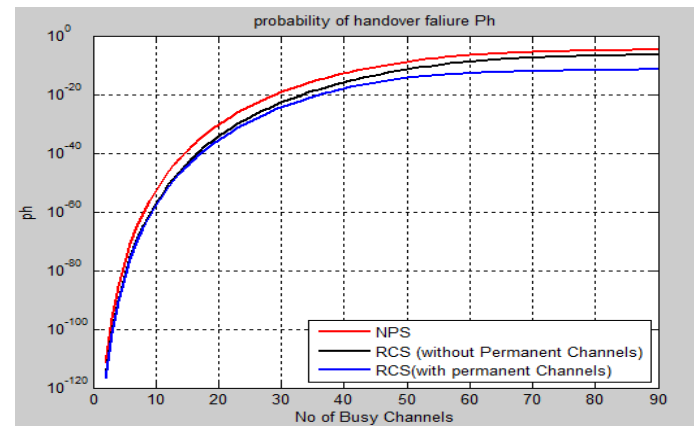

Figure.6.Handover Failure Probability $\left(P_{h}\right)$ with No. of channel $=90, k=10$ and $C_{\mathrm{H}}=15$

\section{FORCED TERMINATION \\ PROBABILITY $\left(\mathbf{P}_{\mathrm{FT}}\right)$ :}

$\mathrm{P}_{\mathrm{ft}}$ for both NPS and RCS in each simulation result in Figures (7,8, and 9) increases with increase in the number of busy channels. In any of these results the order is same as for the results in $\mathrm{Ph}$. Difference is same as explained above that forced termination is also handover failure but after a successful handover.

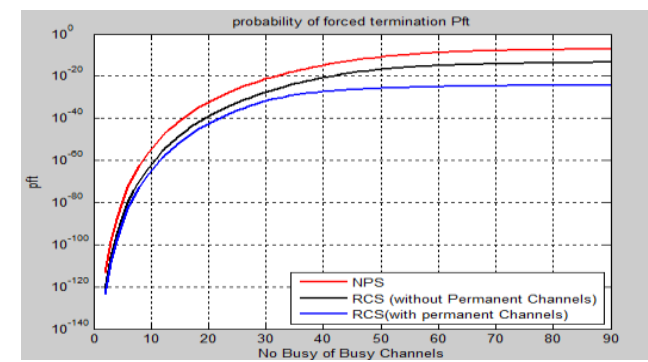

Figure.7.Forced Termination Probability (Pft) with No. of channel= 90, $k=15$ and $C_{\mathrm{H}}=30$.

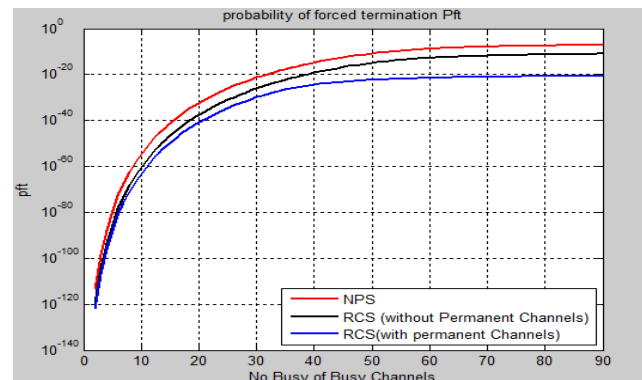

Figure.8.Forced Termination Probability (Pft) with No. of channel= 90, $k=15$ and $C_{\mathrm{H}}=25$

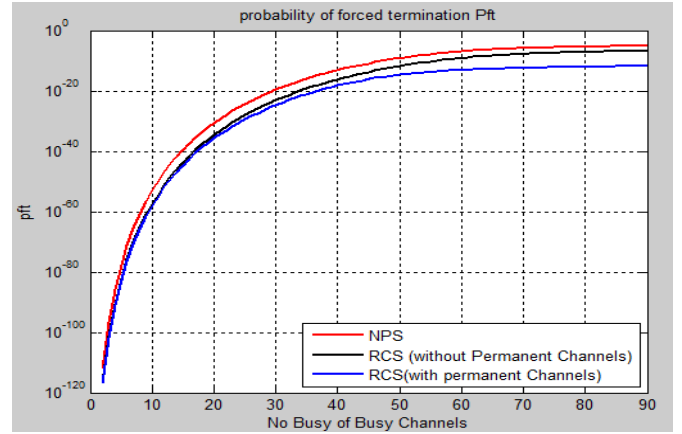

Figure.9.Forced Termination Probability (Pft) with No. of channel=90, $k=10$ and $C_{\mathrm{H}}=15$

\section{PROBABILITY OF NOT COMPLETED CALLS $\left(\mathbf{P}_{\mathrm{NC}}\right)$ :}

Pnc for both NPS and RCS in each simulation result in Figures $(11,12$, and 13) increases with increase in the number of busy channels. These results provide us the information that in which scheme probability of not completed calls was greater due to $\mathrm{Ph}$ and $\mathrm{Pb}$. We see that RCS with permanent channels has faced maximum Pnc. As it is already mentioned before that these curves are not for the permanent jobs so though it has faced higher Pnc still permanent jobs do not face the connection failure. As seen before in this chapter RCS with permanent channels has faced more blocking probability. By adding the handover failure probability to the blocking probability Figure 13 shows that it has given maximum Pnc. Similarly if we add the Phto the $\mathrm{Pb}$ curve of the RCS with no permanent channels, it gives more Pnc than NPS, as shown in Figure 13. As NPS has no permanent or reserved channels, maximum channels are available for handovers and other jobs in the cell; it has faced low Pnc than the other two schemes, as shown in Figure 13.

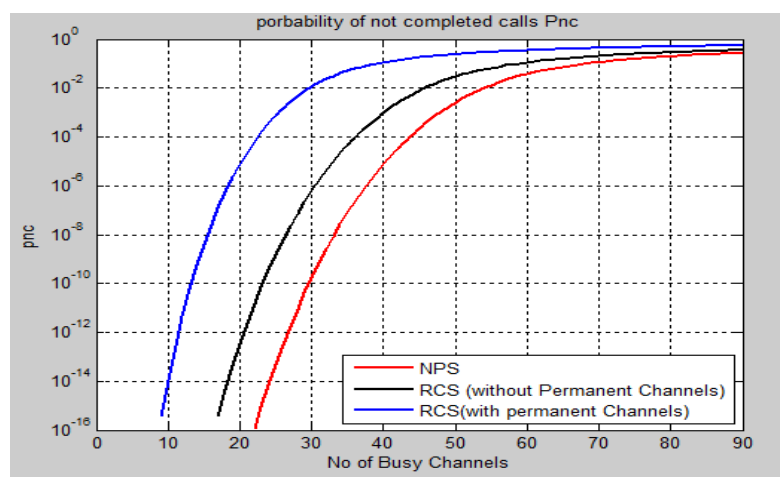

Figure.11 Probability of Not Completed Calls $\left(\mathbf{P}_{\mathrm{nc}}\right)$ with No. of channel $=90, k=15$ and $C_{\mathrm{H}}=30$

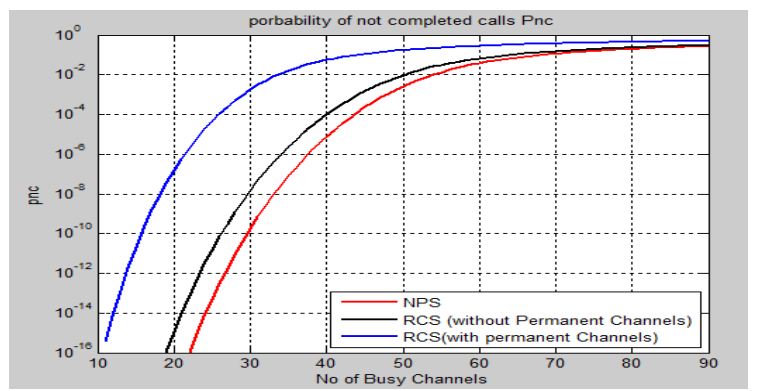

Figure.12 Probability of Not Completed Calls $\left(P_{n c}\right)$ with No. of channel= 90, $k=15$ and $C_{\mathrm{H}}=25$ 


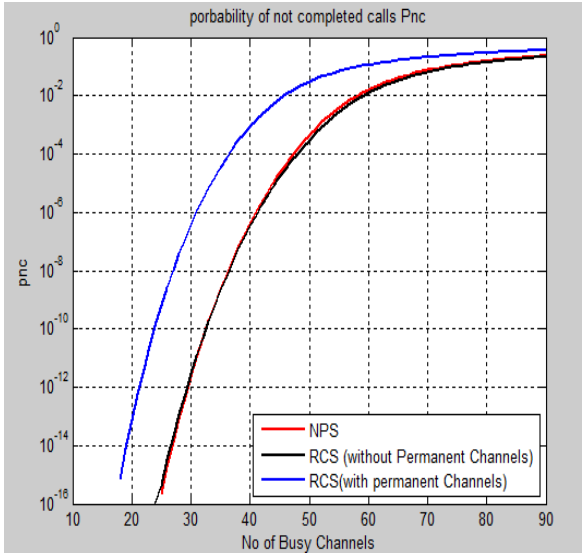

Figure.13 Probability of Not Completed Calls $\left(\mathbf{P}_{\mathrm{nc}}\right)$ with No. of channel=90, $k=10$ and $C_{\mathrm{H}}=15$

\section{CONCLUSION}

After analyzing the simulation result in Wi-max using 90 channels in a cell on the basis of call blocking probability, handover failure, forced termination probability and probability of not completed call it can be easily concluded that overall performance of handoff condition for NPS is better than RCS with permanent channel and RCS without permanent channel. The only drawback is that permanent user will also face blocking as it has same priority for channel allocation for all kinds of jobs in a cell. Moreover, it has been found that RCS should be used in a cell where permanent channels are required to be allocated. Pnc for RCS with permanent channel is highest. It can also be seen that Pnc for NPS outperforms both RCS with permanent channels and RCS without permanent channels. Also in the case of handover failure RCS with permanent channels out performs NPS because RCS has reserved channels for handover purpose which are never allocated to mobile users in the cell.

\section{ACKNOWLEDGEMENT}

I would like to thank my advisor Dr. Rajeev Paulus for his support and encouragement. I would also like to thank Prof. \& Head A.K. Jaiswal to provide valuable advices. The product of this research paper would not be possible without all of them.

\section{REFERENCES}

[1] Antti Makelainen,- "Analysis of Handoff Performance in Mobile Wimax Networks", Dec 2007

[2] IEEE standard for local and metropolitan area networks Part 16: Air Interface for fixed broadband and wireless access system. IEEE Std. 802.16,Oct 2004

[3] F. Peng, B. Peng, and D. Qian-Performance analysis of IEEE 802.11e enhanced distributed channel access,. Communications, IET, vol. 4, no. 9, pp. 728.738, Apr 2010

[4] K. Etemad - Overview of mobile WiMAX technology and evolution,. IEEE Communications Magazine, vol. 46 , no. 10 , pp. $31.40,2008$

[5] Katzela, M. Naghshineh- "Channel assignment schemes for cellular mobile telecommunication systems: a comprehensive survey," IEEE Personal Communications, Volume 3, Issue 3, June 1996

[6] I. Katzella and M. Naghshineh,- "Channel Assignment Schemes for Cellular Mobile Telecommunication systems, A Comprehensive Survey", IEEE Personal Communications Magazine, pp.10-31, June 1996.

[7] Jeffrey G. Andrews, Arunabha Ghosh, RiasmuhamedFundamentals of WiMAX: understanding broadband wireless networking Pearson Education, Inc., 2007

[8] R. Fantacci, -"Performance Evaluation of Prioritized Handoff Schemes in Mobile Cellular Networks", IEEE Transactions on Vehicular Technology, Vol. 49, No. 2, pp. 485-493, March,2000.

[9] Chiapin Wang, Wan-Jhen Yan and Hao-Kai Lo "Dynamic admission control and bandwidth reservation for IEEE 802.16e mobile WiMAX networks" .EURASIP Journal on Wireless Communications and Networking, 2012.

[10] Jing Wang, Mingming Lin,Xuemin Hong, and Jianghong Shi- "QoS Guaranteed Capacity of Centralized Cognitive Radio Networks with Interference Averaging Techniques" Jan, 2014.

[11] Moad Y. Mowafi1, Mamoun F. Al-Mistarihi2, and Mohammad S. Marei- "Cognitive Radio Based Bandwidth Allocation Scheme for WiMAX Networks", Journal Of Communications, Vol. 7, NO. 10, October, 2012. 